\title{
Fetal transcerebellar diameter and transcerebellar diameter - abdominal circumference ratio as a menstrual age independent parameter for gestational age estimation with grading of cerebellar maturity
}

\author{
Gaurav Sharma*, Rita Ghode
}

Department of Radio diagnosis, Datta Meghe Institute of Medical Sciences, JNMC Sawangi (Meghe), Wardha Maharashtra, India

Received: 14 November 2015

Accepted: 28 November 2015

*Correspondence:

Dr. Gaurav Sharma,

E-mail: drgsharma78@gmail.com

Copyright: (c) the author(s), publisher and licensee Medip Academy. This is an open-access article distributed under the terms of the Creative Commons Attribution Non-Commercial License, which permits unrestricted non-commercial use, distribution, and reproduction in any medium, provided the original work is properly cited.

\begin{abstract}
Background: It is important for achieving an uneventful gestation to have a sensitive, specific and age independent obstetric biometric parameter which stays constant throughout the gestation. Transcerebellar diameters (TCD), TCD/ abdominal circumference (AC) ratio are reliable, constant predictors to assess the gestational age and to evaluate fetal growth. Along with TCD, the morphology of the cerebellum also changes gradually with the advancing gestation. The aim of the study was to evaluate TCD and TCD/AC ratio in singleton uncomplicated pregnancy in assessing fetal gestational age and growth and to evaluate the morphological changes in the appearance of the cerebellum with advancing gestation and categorizing it into three grades system.

Methods: Prospective cross sectional study carried out in 100 singletons uncomplicated pregnancy between 12-40 weeks of gestation attending antenatal ultrasound clinics of DMIMS Sawangi, Wardha. Morphology of cerebellum was studied and categorized on USG with measurement of TCD, AC, and TCD/AC ratio.

Results: There was a significant linear correlation of TCD; AC with GA.TCD/AC ratio for normal fetal growth with gestational age from 12-40weeks was found to be constant with a mean of 13.75.Cerebellar grading was $27 \%$ in grade I, $40 \%$ in grade II and 33\% in grade III. The median GA and TCD was 18 weeks and 17mm for grade I, 27 weeks and $27 \mathrm{~mm}$ for grade II and 34 weeks and $42 \mathrm{~mm}$ for grade III.

Conclusions: Significant linear relation of TCD with GA indicating the reliability of this biometry in estimating gestational age and assessing fetal growth. TCD/AC ratio remains fairly constant throughout the gestation and is a sensitive gestational age independent parameter and a good predictor for fetal growth monitoring. Ultrasonography of posterior fossa demonstrated gradual morphological changes in the cerebellum.
\end{abstract}

Keywords: Cerebellar grading, Gestational age, TCD/AC, Ultrasonography

\section{INTRODUCTION}

Ultrasonography has become an important modality during the entire gestational period playing a pivotal role in both maternal and fetal wellbeing with a goal of uneventful gestation.
The determination of true gestational age is undoubtfully very important in the management of pregnancy affecting major decisions like time of labour induction, caesarean section. ${ }^{1}$ The commonly used fetal biometric parameters like BPD, HC, AC, FL are nonspecific as they depend upon the proper fetal growth as well on true menstrual age. ${ }^{2}$ The conventional biometric indices are influenced 
in cases of uteroplacental insufficiency were there occurs redistribution of cardiac output with brain sparing effect.

It has been well documented and demonstrated that there is no alteration in the cerebellar blood flow during these conditions of fetal distress, ${ }^{3}$ hence TCD appears to be the most reliable age independent biometry in the evaluation of true gestational age.

During the assessment of IUGR there is a requirement of a biometry which is very sensitive comprising of two parameters having both least and the most sensitive indices.

Campbell S, Thomas $\mathrm{A}^{4}$ explained that in IUGR foetuses, $\mathrm{AC}$ is most sensitive to get affected early secondary to reduction of hepatic glycogen and subcutaneous fat stores. Therefore the TCD/AC ratio would be useful in patients with unknown gestational age to diagnosed alteration in normal fetal growth permitting a timely intervention.

The present prospective study is aimed to evaluate the correlation between TCD and GA, to calculate the mean TCD/AC ratio and their variation throughout the gestation.

With an evolving dedicated obstetric ultrasonography, there has been a great deal of development in the evaluation of fetal posterior fossa both in term of newly developed highly sensitive biometry and congenital anomalies scan. The fetal cerebellum in particular changes its appearance with the advancing gestational age. These gradual maturity changes include changes in both morphology and echogenicity, coinciding with the histological fetal cerebellar development. ${ }^{5}$ The present study was undertaken to evaluate the changes in the appearance of the cerebellum with age and grading its maturity.

\section{METHODS}

Fetal TCD, AC and TCD/AC ratio was recorded from the Ultrasonographic examination of 100 pregnant mothers attending antenatal clinics of DMIMS Sawangi between 12-40 weeks of gestation.

\section{Inclusion criteria}

1. Normal singleton pregnancies of $12-40$ weeks with known last menstrual period.

2. Normal singleton pregnancies of $12-40$ weeks having previous USG reports consistent with LMP.

\section{Exclusion criteria}

1. Presence of congenital malformation.

2. Discrepancy of 2 weeks or more between gestational age by LMP and USG.

3. Multiple pregnancies.
Sonogram was performed using 3.5-5 $\mathrm{MHz}$ curvinear array transducer on Aloka Alpha-7 machine with single and same operator.

TCD was measured using electronic callipers in outer-toouter fashion as described by Goldstein. ${ }^{6}$

AC was measured on trans axial view at the level of the junction of the umbilical vein with the left portal vein. All measurements were quantified in millimetres.

TCD/AC ratio was calculated by dividing TCD by the AC and multiplying by 100 .

Statistical analysis was performed to measure mean TCD, mean $\mathrm{AC}$, mean $\mathrm{TCD} / \mathrm{AC}$ ratio and standard deviation $\mathrm{SD}$ of TCD/AC. Linear regression was calculated for TCD and plotted to determine the relationship between TCD and the gestational age. Both Correlation Coefficient $\mathrm{r}$ and Coefficient of determination $\mathrm{R}$ square was calculated for TCD.

Simultaneous categorization of morphological variation of cerebellum was also done into three grading system as described by Hashimoto L et al. ${ }^{7}$

\section{RESULTS}

The complete data set was divided into nine groups according to the gestational age, from 12 weeks to 38 weeks of gestation. The data of mean of TCD, AC and $\mathrm{TCD} / \mathrm{AC}$ ratio is depicted in (Table 1).

The mean TCD and mean AC both showed a linear relationship with gestational age in weeks, as shown in scattered diagram (Figure 1).

A high degree of correlation between TCD and gestational age was inferred from a calculated correlation coefficient $\mathrm{r}$ of +0.96625 with $\mathrm{p}<0.001$, which was statistically significant. The coefficient of determination $\mathrm{R}$ square was 0.9336 indicating that $93 \%$ of the transcerebellar diameter can be explained by the gestational age which is very large and significant.

A strong correlation was also found between gestational age and $\mathrm{AC}$ as well (Coefficient of determination $\mathrm{R}$ square $=0.9774)$.

The TCD/AC ratio remained constant throughout pregnancy when compared to the gestational age in all 100 patients (Mean: 13.75; Median: 13.74). GroupWise mean TCD/AC ratio with standard deviation and $10^{\text {th }}$, $50^{\text {th }}, 90^{\text {th }}$ percentiles is depicted in (Table 1 ).

We were successful in evaluating posterior fossa in all 100 patients in terms of cerebellar morphology. Out of 100 patients, 27(27\%) was assigned grade 1, $40(40 \%)$ was assigned as grade II and $33(33 \%)$ was assigned as grade III cerebellar maturity (Table 2). 
The cerebellar grading clearly changed progressively from I to III with advancing gestation.
The median GA and TCD was 18 weeks and $17 \mathrm{~mm}$ for grade I, 27 weeks and $27 \mathrm{~mm}$ for grade II and 34 weeks and $42 \mathrm{~mm}$ for grade III.

Table 1: Gestational age and mean measurements in 100 patients.

\begin{tabular}{|lllllllll|}
\begin{tabular}{|l} 
Gestational \\
Age(weeks)
\end{tabular} & $\begin{array}{l}\text { No. } \\
\text { of } \\
\text { Pat }\end{array}$ & $\begin{array}{l}\text { Mean } \\
\text { TCD } \\
(\mathbf{m m})\end{array}$ & $\begin{array}{l}\text { Mean } \\
\text { AC } \\
(\mathbf{m m})\end{array}$ & $\begin{array}{l}\text { Mean } \\
\text { TCD/AC } \\
(\mathbf{m m})\end{array}$ & $\begin{array}{l}\text { SD } \\
\text { TCD/AC }\end{array}$ & $\begin{array}{l}10^{\text {th }} \\
\text { percent } \\
\text { TCD/AC }\end{array}$ & $\begin{array}{l}\mathbf{5 0}^{\text {th }} \\
\text { percent } \\
\text { TCD/AC }\end{array}$ & $\begin{array}{l}90^{\text {th }} \\
\text { Percent } \\
\text { TCD/AC }\end{array}$ \\
\hline $12-14$ & 8 & 13.062 & 93.625 & 13.68 & 0.337 & 13.36 & 13.68 & 14.10 \\
\hline $15-17$ & 8 & 15.687 & 114.75 & 13.76 & 0.370 & 13.27 & 13.89 & 140.8 \\
\hline $18-20$ & 13 & 18.984 & 141 & 13.50 & 0.446 & 13.10 & 13.44 & 14.08 \\
\hline $21-23$ & 6 & 22.433 & 166.5 & 13.73 & 0.478 & 13.24 & 13.68 & 14.28 \\
\hline $24-26$ & 11 & 26.609 & 194.54 & 13.80 & 0.387 & 13.38 & 13.8 & 14.28 \\
\hline $27-29$ & 14 & 30.828 & 224 & 13.85 & 0.439 & 13.21 & 13.84 & 14.28 \\
\hline $30-32$ & 13 & 39.384 & 285 & 13.81 & 0.451 & 13.47 & 13.6 & 14.45 \\
\hline $33-35$ & 17 & 42.547 & 313.29 & 13.77 & 0.493 & 13.19 & 13.68 & 14.52 \\
\hline $36-38$ & 10 & 46.231 & 334.2 & 13.75 & 0.362 & 13.36 & 13.84 & 13.98 \\
\hline
\end{tabular}

\section{DISCUSSION}

According to UNICEF, globally about 800 women die every day of preventable causes related to pregnancy and childbirth; $20 \%$ of these deaths are from India. To achieve an uneventful gestation with a healthy mother and baby particularly in extremes of fetal growth, it is essential to determine accurately the gestational age and the expected date of delivery, both of which essentially determine important management issues especially with regards to mode of delivery, planned induction of labour or planning for caesarean section.

Assessing an accurate gestational age is more important in our country, where large patients are unaware of the LMP and its importance.

Table 2: Cerebellar grading.

\begin{tabular}{|cccc|}
\hline $\begin{array}{c}\text { Gestational } \\
\text { Age Group } \\
\text { (weeks) }\end{array}$ & $\begin{array}{l}\text { Grade I } \\
\text { N: } 27\end{array}$ & $\begin{array}{c}\text { Grade II } \\
\text { N: } 40\end{array}$ & $\begin{array}{c}\text { Grade III } \\
\text { N: } 33\end{array}$ \\
\hline $\begin{array}{c}12-20 \\
(\mathrm{n}: 29)\end{array}$ & 22 & 7 & - \\
\hline $\begin{array}{c}21-30 \\
(\mathrm{n}: 33)\end{array}$ & 5 & 23 & 5 \\
\hline $\begin{array}{c}31-40 \\
(\mathrm{n}: 38)\end{array}$ & - & 10 & 28 \\
\hline
\end{tabular}

Conventional Ultrasound biometry like BPD, FL, and HC are nonspecific with limitations in setting of inconsistency between clinical and USG age. These parameters are also influenced by fetal growth, configuration of skull and external compressive forces as in abnormal presentations.
The fetal cerebellum is easily visualised at 11 weeks of gestation and onwards. ${ }^{6}$ The blood circulation to cerebellum is relatively preserved in fetus with uteroplacental insufficiency secondary to brain sparing effect and redistribution of cardiac output. Also the cerebellum is well protected between petrous ridges nullifying the external compressive forces. Because of these two features, the measurement and correlation of Transcerebellar diameter is more specific biometry which is age independent. ${ }^{8-10}$

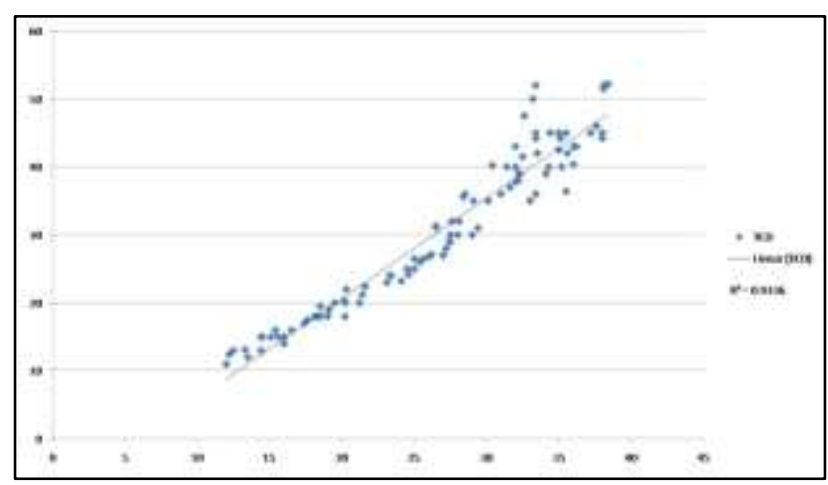

Figure 1: Scatter plot showing relationship between TCD and GA.

The transcerebellar diameter in our study showed a significant linear variation with the advancing age with coefficient of determination $\mathrm{R}$ square of 0.933 .

Chavez MR, Ananth CV et al in 2007 concluded that TCD nomogram is reliable and accurate in predicting gestational age even at extremes of the fetal growth. ${ }^{9}$ 
Malik R, Pandya VK et $\mathrm{al}^{11}$ showed a $92 \%$ predictive accuracy of TCD for gestational age as compared to the standard nomogram by Chitty et al. ${ }^{12}$

Reece EA et $\mathrm{al}^{13}$ in their study indicated that growth of transcerebellar diameter is unaffected by growth retardation thus TCD serves as age independent and reliable correlate of gestational age against which potential deviation of growth may be compared.
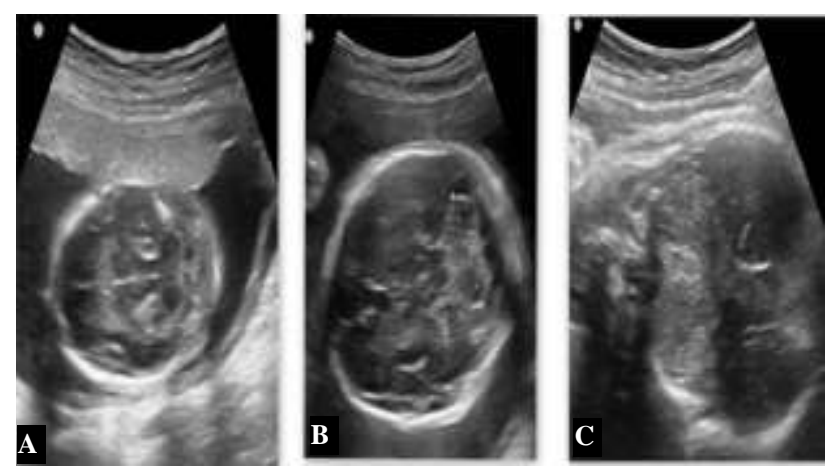

Figure 2: Spot US images of posterior fossa with Gr I (A), Gr II (B), and Gr III (C) cerebellum with advancement from a fluid filled cystic eyeglass appearance to dumbbell configuration and final homogenous echogenic solid cerebellar tissue.

Our study also established a linear relation of TCD with GA indicating the reliability of this biometry in estimating gestational age and assessing fetal growth.

In the IUGR foetuses there is more pronounced reduction of hepatic glycogen and subcutaneous fat stores leading to an early alteration and reduction in AC measurement. ${ }^{4}$

Therefore the ratio of TCD/AC will provide a sensitive method of detecting IUGR particularly asymmetrical and is useful in evaluation of gestational age in cases with unknown or inconsistent LMP for early and prompt intervention. $^{14-16}$

In our study of 100 pregnancies also, the TCD/AC ratio remained constant throughout various gestations with mean value of 13.74 with mean SD of 0.433 .

Malik R, Pandya V k et al ${ }^{11}$ and Haller H, Petrovic O et $\mathrm{al}^{17}$ suggested a TCD/AC ratio $2 \mathrm{SD}$ above the mean as a sensitive and age independent predictor of IUGR.

Campbell WA et $\mathrm{al}^{14}$ showed a linear relationship between TCD and AC which is stable during the pregnancy and is age independent.

Similarly Dilmen G et al in their study of 330 pregnant women found a very close relation of TCD with GA (r: 0.9767 and R2: 0.9539). The mean TCD/AC ratio was $14.3+/-0.0106(\mathrm{SD})$ which remained fairly constant. ${ }^{15}$
Meyer et al found strong correlation existed between GA and TCD, mean TCD/AC ratio being 13.6, which remained constant throughout the pregnancy, similar to the findings of our study. ${ }^{16}$

Campbell et al, Dilmen G et al, Haller et al and Snijders et al in their respective studies found a constant TCD/AC ratio with mean value of $13.7,14.3,14.4$ and 13.7 respectively. ${ }^{14,15,17,18}$

Wesley Lee et al observed that $\mathrm{TCD} / \mathrm{AC}$ ratio is fairly constant throughout gestation and found it to be a good biometry to diagnose asymmetric IUGR. ${ }^{19}$ They also pointed out that this ratio is not sensitive in cases with symmetric growth retardation where both TCD and AC may be equally affected.

McLeary RD, Kuhns LR et al highlighted the importance of the imaging of posterior fossa. ${ }^{5}$ They stated that the size of the cerebellum or TCD is important useful biometry in gestational age evaluation especially in cases with craniosynostosis.

There is a gradual histologic morphological change in human cerebellum with advancing gestational age which can be monitored with USG.

Grading of the cerebellum is well documented and classified as: ${ }^{7}$

Grade I: Each cerebellum is round; vermis not developed together giving "a pair of eyeglasses" appearance. At this time hemisphere lacks echogenicity, appearing as two fluid containing cysts (Figure 2A).

Grade II: Vermis develops as an echogenic rectangular tissue with "dumbbell" appearance. Echogenicity begins to starts from the margin (Figure 2B).

Grade III: Hemisphere appears as triangular or fan shaped. Echogenicity of central and peripheral portion become same giving rise to a solid tissue texture (Fig 2 C).

In our study also there is a progressive change in the cerebellar maturity with advancing GA.

The predominant cerebellar grade was grade I up to 20weeks, grade II up to 31 weeks and grade III thereafter.

The gradual change in the morphology of the cerebellum is correlated with the degree of Purkinje cell differentiation and alteration in the water content of the cerebellar tissue. $^{20}$

The cerebellar grading is also important in chromosomal abnormalities like Trisomy 21, 18 were there is restriction of the development in size and tissue maturation which can be detected with Ultrasound grading. ${ }^{21}$ 
Maternal steroid administration and maternal diabetes also affects the fetal cerebellar development which can be monitored with this grading system.

\section{CONCLUSION}

The significant linear correlation between GA and TCD has shown that TCD is a reliable obstetric biometric parameter for estimation of true gestational age. The result of this study indicated that $\mathrm{TCD} / \mathrm{AC}$ ratio remain fairly constant throughout the gestation and is a sensitive gestational age independent parameter which can also be a good predictor of IUGR especially in asymmetrical growth alteration. The cerebellar grading system can be useful to evaluate the normal development as well as in identifying abnormal growth and maturation in normal and complicated gestation.

\section{Funding: No funding sources}

Conflict of interest: None declared

Ethical approval: Not Required

\section{REFERENCES}

1. Kramer MS, Mclean FM, Boyd ME, Usher RH. The validity of gestational age estimation by menstrual dating in term, preterm, and post term gestation. JAMA. 1988;260(22):3306-8.

2. Meyer WJ, Gauthier D, Ramakrishnan V, Sipos J. Ultrasonographic detection of abnormal fetal growth with the gestational age: Independent transverse cerebellar diameter to abdominal circumference ratio. Am J Obstet Gynecol. 1994;171(4):1057-63.

3. Behrman RE, Lees MW, Peterson ED. Distribution of the circulation in the normal and asphyxiated fetal primate. Am J Obstet Gynecol. 1970;108(6):956-9.

4. Campbell S, Thomas A. Ultrasound measurement of the fetal head to abdomen circumference in the assessment of growth retardation. $\mathrm{Br} \mathrm{J}$ Obstet Gynecol. 1977;84(3):165-74.

5. McLeary RD, Kuhns LR, Barr M Jr. Ultrasonography of the fetal cerebellum. Radiology. 1984;151(2):439-42.

6. Goldstein I, Reece EA, Pilu G, Bovicelli L. Cerebellar measurements with ultrasonography in the evaluation of fetal growth and development. Am J Obstet Gynecol. 1987;156(5):1065-9.

7. Hashimoto K, Shimizu T, Shimoya K, Kanzaki T et al. Fetal cerebellum: US appearance with advancing gestational age. Radiology. 2001;22(1):70-4.

8. Chavez MR, Ananth CV, Smulian JC, Yeo L, et al. Fetal transcerebellar diameter measurement with particular emphasis in the third trimester: A reliable predictor of gestational age. Am J Obstet Gyneco. 2004;191:979-84.
9. Chavez MR, Ananth CV, Smulian JC, Vintzileos AM. Fetal transcerebellar diameter measurement for prediction of gestational age at the extremes of fetal growth. J Ultrasound Med. 2007;26(9):1167-71.

10. Davies MW, Swaminathan M, Betheras FR. Measurement of the transverse cerebellar diameter in preterm neonates and its use in assessment of gestational age. Australas Radio. 2001;45(3):309-12.

11. Malik R, Pandya VK, Shrivastava P. Gestational age estimation using transcerebellar diameter with grading of fetal cerebellum and evaluation of $\mathrm{TCD} / \mathrm{AC}$ ratio as a gestational age independent parameter. IJRI. 2003;13(1):95-7.

12. Altman DG, Chitty LS: Charts of fetal size methodology. Br. J Obstet Gynecol. 1994;101(1):2934.

13. Reece EA, Goldstein I, Pilu G, Hobbins JC. Fetal cerebella growth unaffected by intrauterine growth retardation. 1978;157(3):632-8.

14. Campbell WA, Nardi D, Vintzileos AM, Rodis JF. Transverse cerebellar diameter/abdominal circumference ratio throughout pregnancy: A gestational age independent method to assess fetal growth. The Am Coll Obstet Gynecol. 1991;77(6):893-97.

15. Dilmen G, Toppare MF, Turhan NO, Ozturk M. Transverse cerebellar diameter and transverse cerebellar diameter/abdominal circumference index for assessing fetal growth. Fetal Diagn Ther. 1996;11(1):50-6.

16. Meyer WG, Gauthier DW. The fetal TCD/AC ratio: a gestational age independent method of assessing fetal size. J Ultrasound Med. 1993;12(7):379-82.

17. Haller H, Petrovic O, Rukavina B. Fetal transverse cerebellar diameter/abdominal circumference ratio in assessing fetal size. Int $\mathbf{J}$ Gynecol Obstet. 1995;50(2):159-63.

18. Snijders RJM, Nicolaides KH. Fetal biometry at 1440weeks of gestation. Ultrasound Obstet Gynecol. 1994;4(1):34-8.

19. Wesley Lee, Scott Barton Christine H. Transverse cerebellar diameter- A useful predictor of gestational age for foetuses with asymmetric growth retardation. Am J Obstet Gynecol. 1991;165(4):1044-50.

20. Zecevic N, Rakic P. Differentiation of Purkinje cells and their relationship to other components of developing cerebellar cortex in man. J Comp Neurol. 1976;167(1):27-47.

21. Hill LM, Marchese S, Peterson C, Fries J. The effect of Trisomy 18 on transcerebellar diameter. Am J Obstet Gynecol. 1991;165(1):72-5.

Cite this article as: Sharma G, Ghode R. Fetal transcerebellar diameter and transcerebellar diameter abdominal circumference ratio as a menstrual age independent parameter for gestational age estimation with grading of cerebellar maturity. Int J Reprod Contracept Obstet Gynecol 2015;4:2036-40. 